\title{
Música de fronteira, música de memória: o experimentalismo de DJs pela Semiótica da Cultura
}

\author{
Herom Vargas \\ https://orcid.org/0000-0002-7837-6740 \\ Nilton Faria de Carvalho' \\ http://orcid.org/0000-0003-2443-6418 \\ I - UMESP \\ São Paulo (SP), Brasil
}

Resumo: $\mathrm{O}$ artigo analisa peças musicais de DJs experimentais a partir de duas categorias relacionadas à semiótica da cultura: semiosfera e suas fronteias; e memória da cultura, desenvolvidas pelo semioticista russo I. Lotman. São discutidas as características da música eletrônica de pista, seus subgêneros e as diferenças colocadas em experimentações produzidas por esses DJs. O corpus de análise é formado por composições de três artistas: DJ Tudo, Psilosamples e Dandara. A argumentação e a análise demonstram a efetividade dessas duas categorias para o entendimento das dinâmicas produtiva e criativa desse tipo de trabalho que destoa do mainstream da música pop eletrônica.

Palavras-chave: música eletrônica; DJ; experimentalismo; semiótica da cultura.

Abstract: Border music, music of memory: DJs' experimentalism through the Semiotics of Culture

- The paper analyzes musical pieces of experimental DJs from two categories related to the semiotics of culture: semiosphere and its borders and memory of culture, developed by the Russian semioticist I. Lotman. The discussion is about the characteristics of electronic dance music, its subgenres, and the differences put in experimentations produced by these DJs. The corpus of analysis is formed by compositions of three artists: DJ Tudo, Psilosamples and Dandara. The argument and the analysis demonstrate the effectiveness of these two categories for the understanding of the productive and creative dynamics of this kind of work that differs from the mainstream of electronic pop music.

Keywords: electronic music; DJ; experimentalism; semiotics of culture. 


\section{Introdução}

A música pop é produto midiático cujos significados são construídos no rico campo cultural das mediações. Sua configuração a partir de múltiplos textos pode, em dois limites opostos, reforçar formas hegemônicas na cultura ou permitir fissuras para negociações de novas representações. Por sua capilaridade na sociedade, pela circulação e consumo, é capaz de traduzir informações de distintos campos da cultura, de tempos e espaços distantes. Ligada à lógica do mercado, a música pop traz em sua materialidade (sons, palavras, cantos e performances) diversas experiências comunicacionais e estéticas. Seu território cultural é marcado pelas constantes rearticulações dentro da cultura da mídia, caracterizada por Douglas Kellner (2001, p. 34) como "terreno de disputa que reproduz em nível cultural os conflitos fundamentais da sociedade".

A era digital intensificou essas articulações com o uso de equipamentos que gravam amostras sonoras, recortam e editam, sintetizam e simulam timbres. A música eletrônica produzida por DJs (disc jockeys), no universo do pop, é exemplo disso. Fundada nos procedimentos de seleção, apropriação e colagem, bem como no uso de discos, aparelhos digitais, computadores e softwares de produção sonora como "instrumentos musicais", essa música tem ampliado os processos de experimentação. Na produção do DJ, a peça é construída com novos parâmetros, especialmente na articulação de:

\section{[...] timbres, texturas, espacialidades, ritmo e repetição, como um componente de um sistema, que deve funcionar dentro do ambiente de festas, buscando levar as pessoas ao êxtase através da alteração e intensificação de sensações físico- corpóreas (PEREIRA DE SÁ, 2003, p. 161).}

A mistura e a colagem possibilitaram hibridismos e trânsitos sonoros entre culturas. A maior parte dessas músicas foi criada a partir do andamento (ou beat) para a dança; outras são frutos de projetos estéticos mais ou menos definidos ${ }^{1}$. Para usar um conceito importante na semiótica da cultura, tal produção musical se organiza pela dinâmica da fronteira, definida por luri Lotman (1996) como uma região de contato entre dois ou mais sistemas semióticos e culturais, formada por filtros tradutores que incorporam elementos de um sistema a outro e vice-versa. A própria ideia de música nômade, plena em contatos para produção de sínteses, faz-nos retomar dois pontos da semiótica da cultura: a noção dinâmica de cultura com seus processos tradutórios e seus mecanismos de semioses; e os acionamentos das memórias da cultura, ambos desenvolvidos pelo semioticista I. Lotman, na Escola de Tártu-Moscou, a partir dos anos 1960.

1 Obviamente, esses dois polos são extremos abstratos e conceituais do mesmo procedimento. A riqueza da música eletrônica está na vasta gama de possibilidades criativas ao longo dessa linha imaginária, sobretudo mais próxima ao polo experimental. 
Esses aspectos de mistura na música eletrônica são determinantes na produção dos DJs aqui analisados, pois caracterizam modos de criação que reúnem (ou friccionam) diversidades de culturas locais - às vezes, consideradas world music ou música étnica -, cujos resultados apontam para diferenças frente aos elementos sonoros e culturais dos subgêneros da música pop eletrônica de pista que reforçam identidades euro-americanas já partilhadas e reconhecidas. Além disso, fazem-nos pensar na teoria semiótica de Lotman como ferramental teórico-conceitual produtivo para o entendimento dessa dinâmica compositiva e dos sentidos construídos. Para tanto, a reflexão que aqui se propõe é sobre como entender a música eletrônica de alguns DJs mais experimentais a partir de dois conceitos da semiótica da cultura, transformados aqui em categorias de análise: a) semiosfera e suas características; b) memória da cultura e cultura como memória. Enfatizamos o que chamamos de DJs produtores experimentais, ou seja, aqueles que atuam além de uma cultura de pista herdeira das diferentes cenas e subgêneros da música pop eletrônica mainstream. Como objeto de análise, dentre muitos que atuam sob tais registros, escolhemos três DJs cujas obras se fundamentam em projetos criativos mais conceituais: DJ Tudo, Psilosamples e Dandara.

\section{Música eletrônica, DJ e experimentalismo}

Quando falamos em música eletrônica, tratamos da música produzida dentro da categoria música pop de dança criada em processos de ressignificação que reúnem variados referenciais, como o hip hop, o dub jamaicano e sua cultura sound system e o rock, bem como a disco music de produtores como Giorgio Moroder e os experimentos realizados pelo grupo alemão Kraftwerk². Sua construção se fundamenta na relação entre DJ e público jovem no ambiente das festas, onde música, dança, corpo e performance são os principais códigos de interação.

A música eletrônica dos DJs rompeu com a ideia, construída pela evolução da fonografia do século XX, de uma faixa gravada em um disco long play (LP). Ao contrário, ela é pensada para ser tocada ao vivo, com duração estendida pelo tempo em que agradar a plateia. A obra é performada a partir de trechos pré-gravados, alterados e misturados ${ }^{3}$.

Além da dança e da festa, uma das bases dessa música é o ostinato, repetição de uma célula rítmica ou melódica cujos parâmetros sonoros (timbre, andamento, saturação, reverberação etc.) são alterados, ao longo da execução. As repetições, sempre acionadas pela subjetividade do DJ na relação com o público, têm seus fragmentos muitas vezes retirados de outros fonogramas, como apropriações criativas de peças de outros artistas.

2 Eduardo Navas considera que o hip hop e os ritmos jamaicanos abriram caminho para experimentos posteriores inseridos na linguagem da música pop eletrônica: "dub e reggae juntos com o hip-hop foram as principais influências no desenvolvimento do drum ' $n$ ' bass, bem como o trip-hop" (NAVAS, 2012, p. 48). Sobre música eletrônica, ver também Ferreira e Rabot (2017). (As citações em inglês foram traduzidas pelos autores).

3 "A gravação deixou de ser o principal fim ou referência musical. Não é mais do que um traço efêmero (destinado a ser sampleado, deformado, misturado) de um ato particular no seio de um processo coletivo" (LEVI, 1999, p. 142). 
O terceiro aspecto é a "batida" (pulso, andamento ou beat), elemento rítmico que pauta o tempo, parâmetro vital da música que conecta o DJ à plateia. Expresso em batidas por minutos (bpm), é, com a sonoridade, um dos principais parâmetros para definição dos gêneros e subgêneros dentro da música eletrônica: tecno, house, drum'n'bass etc. O quarto elemento básico, estabelecido na cultura pop pelos DJs do rap, é a colagem ou sampling (sampleamento), procedimento de seleção e "costura" de amostras sonoras, reconhecíveis ou não. É resultado do uso do sampler, equipamento que digitaliza trechos musicais para tocá-los de forma modulada. Porém, a complexidade dessa prática aponta para outros sentidos. Mais do que repetição, sampling é a criação de diferença e ressignificação, outro devir, um fragmento deslocado que produz informação, de um lado, pelo sentido cultural ou por seu contexto de origem, e de outro, pelo atrito semântico que provoca no discurso. O sample
[...] é como uma citação bibliográfica sem referência (a não ser que o ouvinte a reconheça de imediato). Não é uma crítica ao zeitgeist, mas uma atualização do passado. Um processo de diferenciação. [...] Cada sample [...] não é como um texto escrito, um discurso, mas um conceito. Se o nome próprio não pertence à linguagem, o sample também não pertence à linguagem musical, já que não pode ser transcrito numa partitura (CONTER; SILVEIRA, 2014, p. 56).

Se o modus operandi está dado, a mistura sonora específica é produto da criatividade do DJ, sua habilidade, seu repertório cultural e da pesquisa musical que desenvolve. No entanto, a música pop eletrônica de pista enquanto gênero, mais ligada ao mainstream pop de sucesso ${ }^{4}$ (talvez macrogênero), está constituída sobre uma cultura ocidental de produção, circulação e consumo de música popular organizada em subgêneros e cenas musicais que compõem historicamente certa força narrativa, de estabilidade e reconhecimento. O DJ produtor de perfil experimental, que destacamos aqui, mesmo vinculado à dinâmica da festa (embora não seja a mesma festa), cria suas peças a partir de referências culturais mais amplas e busca timbres, batidas ${ }^{5}$ e sons a partir de pesquisas sonoras e samplings que remetem a culturas menos conhecidas, na tentativa de se afastar dos padrões mais convencionais da música pop eletrônica e atravessar seus subgêneros ${ }^{6}$. Neste artigo, tomamos como objeto o DJ produtor de projeto mais conceitual e criativo, que força os limites das categorizações e sugere novas experiências estéticas e culturais.

4 Como exemplos de DJ mainstream, citamos três: Diplo: <https://www.youtube.com/watch?v=xF9LEB3-k_s>; David Guetta: <https://www.youtube.com/watch?v=VKtTSoC7o2l>; El Diablo: <https://www.youtube.com/ watch? $v=$ EHXoySEGRR8 $>$.

5 Alguns levam suas experimentações a limites em que o beat, elemento básico do grande gênero, é questionado e suplantado. Esta e outras formas criativas podem ser ouvidas, como exemplo, no trabalho do grupo Medula Sonora, em um projeto de pesquisa sonora mais amplo. Ver detalhes em: <https://www.facebook.com/pg/ medulasonora/about/?ref=page_internal $>$.

6 Dois exemplos de espaços importantes que marcam o experimentalismo na música eletrônica são o festival Kino Beat, cuja $5^{a}$ edição ocorreu em novembro de 2018, no Rio Grande do Sul, e o I Encontro de Selos de Música Experimental (ESME), ocorrido em 2018, em Salvador. 
As produções experimentais articulam diferentes informações culturais, entre gêneros musicais, seus arsenais de significação, tradições e culturas não ocidentais "enquadradas" mercadologicamente como world music ou música étnica. Nesses trabalhos, a junção de estilemas da música eletrônica com os de outras tradições tende a desestabilizar os mecanismos de reconhecimento sonoro, codificados na organização mercadológica da música pop em geral. É preciso pensar, no entanto, que leituras mais imediatas baseadas nos gêneros musicais geralmente levam em conta seus aspectos de estabilidade moldados no consumo, mas o processo criativo que os configura como formas culturais é sempre dialógico e intertextual ${ }^{7}$. Por isso, cabe retomar a noção bakhtiniana de gênero, retrabalhada por Julia Kristeva (1980, p. 65), como intertextualidade, inerente à criação artística, ao considerar o texto "uma intersecção de superfícies textuais em vez de um ponto (um significado fixo)". Ao serem organizados, os gêneros passam a ser também discursivos (BAKHTIN, 2003), aspecto que será consistente no processo de midiatização dos gêneros musicais (sobretudo os fonográficos ${ }^{8}$ ), na cultura midiática e nas apropriações culturais.

No caso dos incontáveis subgêneros da música pop eletrônica, os processos de nomeação são conduzidos, algumas vezes, com objetivos exclusivamente mercadológicos, o que para Kembrew McLeod (2001, p. 71) é "compatível com a lógica do consumo e obsolescência planejada", vez que, para as indústrias midiáticas, os produtos culturais tendem a reforçar e suprir demandas por "novidades". E, quanto à organização das comunidades musicais, muitas das divisões em subgênero, para Simon Reynolds (1999, p. 7), somente fazem sentido "se você já é participante do discurso" oferecido por um dado gênero ou cena. Outro aspecto a ser observado é que mesmo com as reconfigurações nas formas de consumo e de acesso à música pop, como sites e redes sociais, por meio dos quais há compartilhamentos de conteúdos e sociabilidades (POLIVANOV, 2014), as discussões e organizações das cenas ocorrem apoiadas, geralmente, nas expressões musicais reconhecíveis, inscritas pelos subgêneros da música pop eletrônica.

O DJ produtor experimental não constrói sua obra dentro dos territórios de sentido mais fechados dos gêneros musicais conhecidos, por mais que estilemas sonoros de um ou outro possam ser decodificados pelo ouvinte. Ao contrário, ele trabalha para além do dialogismo inerente a um gênero específico, mas se posiciona no sentido de produzir rompimentos possibilitados por relações de diversidade textual, muitas vezes radicais. Da mesma forma, pode, inclusive, fugir dos vários subgêneros existentes dentro da música pop eletrônica, por meio de incorporações de ritmos de tradições locais que tendem a desequilibrar os regimes de identificação e projetar neles algumas mudanças.

Nas obras que escapam dos perfis mais estáveis dos gêneros, o percurso criativo do artista põe em evidência signos subterrâneos, distantes ou "estranhos", diferentes

7 O rock e o hip hop, por exemplo, são gêneros organizados a partir de misturas de diferentes vertentes musicais e culturais.

8 Consideramos gênero fonográfico as classificações de gênero musical após o advento da fonografia e com a mercantilização da música popular em fonogramas. 
daqueles previsivelmente articulados - não à toa, canções e ritmos que remetem às tradições e culturas não euro-americanas ("não ocidentais") são classificados em rótulos mercadológicos generalistas e etnocêntricos como world music ou música étnica. Assim, a criação experimental que usa essas outras vertentes sonoras representa um movimento dialético que age sobre a matéria sonora, altera parâmetros de produção, reconhecimento e escuta - os processos comunicacionais da música nas mídias (VALENTE, 2003) e influencia também outros sistemas sociais. A prática experimental do artista com as materialidades musicais ${ }^{9}$ produz diferença, pois não adere à territorialidade semiótica da música pop eletrônica ocidental e sua economia cultural e sonora de cenas e práticas de consumo euro-americanas, subgêneros e festas raves (REYNOLDS, 1999; MCLEOD, 2001), e assume, na linguagem, críticas a valores culturais associados à estabilidade semântica da cultura mainstream.

\section{Três DJs em foco}

Partimos do pressuposto de que as composições de DJs produtores experimentais são dispositivos de criação de diferença, deslocamento de sentidos e provocação de estranhamentos. Na pesquisa que desenvolvemos, os trabalhos de vários DJs ${ }^{10}$ foram analisados a partir de entrevistas e da observação de suas obras. Consideramos que três deles usam os modos de produção da música pop eletrônica para articular tradições locais ${ }^{11}$ e diversidades culturais e, assim, superar a centralidade da música pop eletrônica de sucesso. Longe de serem os únicos, são casos representativos que modelam de maneira exemplar uma forma de fazer música e uma maneira de entender essa produção.

Um desses artistas é o DJ Tudo, codinome de Alfredo Bello, músico formado pela Universidade de Brasília (UnB) e que atuou em bandas de punk rock na juventude. Começou como DJ nos anos 1990 e, nas discotecagens, mixava músicas de sua coleção de discos (hoje, tem cerca de 12 mil LPs). Nos anos 2000, passou a viajar pelo Brasil e por outros países, para fazer registros de manifestações sonoras e conhecer músicos e outras tradições. Esse acervo é parte de seu material de trabalho. Um disco seu importante é Pancada Motor - Manifesto da Festa (2015) ${ }^{12}$.

O segundo é Zé Rolê e seu projeto musical Psilosamples. Natural de Pouso Alegre (MG), traz como referências a música eletrônica de produtores latino-americanos e sons do interior e do mato, fruto de sua origem. Boa parte de suas peças é feita ao vivo,

9 A forma como essas canções experimentais nos tangenciam, sempre numa relação de diferença e alteridade, aproxima-se da proposta de Hans U. Gumbrecht (2010, p. 147) de "experienciar as coisas do mundo na sua coisidade pré-conceitual", no âmbito das percepções e das sensações.

10 DJ CIA (DJ do grupo de rap RZO e tem projetos com Seu Jorge e Ice Blue, dos Racionais MC's), DJ Dandan (DJ do cantor Criolo), DJ Dolores (ligado ao manguebeat, de Recife), DJ Hum, DJ Nuts, DJ Tudo (Alfredo Bello), KL Jay (Racionais MC's), Luana Hansen (DJ e rapper), Rodrigo Gorky (Bonde do Rolê), Tide (SP) e Zé Rolê (projeto musical Psilosamples), Dandara e AIWAA.

11 Além desses três, há também a obra de DJ Dolores, discutida em outro artigo (VARGAS; CARVALHO 2018).

12 Sobre DJ Tudo e a construção de sua performance ao vivo, ver Vargas e Carvalho (2016). 
o que o mantém próximo do caráter performático dos DJs. Trabalha sons regionais, temas e cantigas tradicionais com texturas e efeitos de ambientação sonora ${ }^{13}$.

Dandara (Dominik Traub) é um jovem suíço da Basileia que reúne referências a partir do seu contato com diferentes culturas ao redor do mundo. Fez viagens recentes ao Brasil - de onde tirou a inspiração para seu nome artístico -, e mescla em suas produções ${ }^{14}$ sonoridades de culturas indígenas latino-americanas e tradições de diferentes países africanos.

\section{Duas categorias de análise a partir da semiótica da cultura}

\section{Semiosfera e fronteira}

Para o entendimento da obra desses artistas, articulamos dois conceitos operativos da semiótica da cultura, a partir de I. Lotman. O primeiro é a ideia de semiosfera, que, segundo o autor, é um espaço abstrato em que signos e textos culturais se movimentam, uns influenciando outros que, por sua vez, transformam-se e geram novas sínteses em processos contínuos de produção de sentido. A semiosfera "[...] pode ser vista como um ambiente no qual diversas formações semióticas se encontram imersas em diálogo constante [...]. Não é por acaso que uma das imagens mais utilizadas para representar esse espaço seja justamente uma imagem biológica" (RAMOS et al., 2007, p. 34).

Trata-se de sistema dinâmico e complexo, ao mesmo tempo organizado e irregular, limitado por fronteiras dentro das quais textos da cultura se mantêm em relações produtivas com outros sistemas. Os sistemas culturais, que fazem trocas e se contradizem, subsistem com organizações próprias, ao mesmo tempo em que mudam ao interagirem com outros sistemas. A semiosfera garante certa coerência interna, que a define, mas, mesmo com unidade, tem razoável nível de diversidade e irregularidade internas:

todo el espacio semiótico puede ser considerado como un mecanismo único (si no como un organismo). Entonces resulta primario no uno o otro ladrillito, sino el 'gran sistema', denominado semiosfera. La semiosfera es el espacio semiótico fuera del cual es impossible la existência misma de la semiosis (LOTMAN, 1996, p. 24).

Se dentro de suas fronteiras ocorrem semioses, textos que lhe são externos não produzem sentido já que não operam semioticamente dentro da lógica da semiosfera. Em outras palavras, se textos, linguagens e semioses (a cultura como um todo) são construídos na semiosfera, o que está fora pode ser pensado como não-texto ou não-cultura, ou seja, não faz sentido dentro do campo semiótico delimitado. No entanto, como o movimento desses sistemas é mais ou menos intenso, sempre ocorre de não-textos serem traduzidos a textos quando são traduzidos pelas fronteiras da semiosfera. Assim, o que é externo se torna interno e provoca novas relações e sentidos dentro da semiosfera. Esse é o movimento

13 Ver entrevista do DJ e comentários sobre sua obra em Assef (2016).

14 Trabalhos do artista estão disponíveis em: <https://soundcloud.com/dandaramusic >. 
da fronteira: tanto é linha demarcatória entre interno e externo, cultura e não-cultura, como zona porosa de tradução do externo em interno, do não-texto em texto.

\begin{abstract}
[...] la frontera semiótica es la suma de los traductores-filtros bilíngues pasando através de los cuales un texto se traduce a otro linguaje (o lenguajes) que se halla fuera de la semiosfera dada. El 'carácter cerrado' de la semiosfera se manifiesta en que ésta no puede estar en contacto con los textos alosemióticos o con los no-textos. Para que éstos adquieran realidad para ella, le es indispensable traducirlos a uno de los linguajes de su espacio interno o semiotizar los hechos no-semióticos (LOTMAN, 1996, p. 24).
\end{abstract}

A fronteira é, portanto, região de rica e intensa movimentação, onde ocorrem as mediações. É o espaço da semiose per se. Ao mesmo tempo, pensando no dinamismo da cultura, esses elementos traduzidos também podem alterar, em alguma medida, as características da semiosfera em que entraram. Se tais novidades contaminarem os sistemas internos com razoável força, poderão rearticular o centro da semiosfera, aquele campo em que suas características são mais definidas e plenas. Assim, textos das bordas têm estrutura mais frágil e estão mais aptos à "contaminação", a exercer e receber influências, possibilitando situações para o surgimento de novos textos, diferente do que ocorre no núcleo da semiosfera, campo mais estável.

Na esfera semiótica, nenhum sistema de signo está fechado. Na fronteira, espaço privilegiado da criação artística, os textos adquirem a forma múltipla e porosa típica dos textos mais inovadores que traduzem informações de dentro e de fora, pois são "como un complejo dispositivo que guarda variados códigos, capaz de transformar los mensajes recibidos y de generar nuevos mensajes, un generador informacional que posee rasgos de una persona con un intelecto altamente desarrollado" (LOTMAN, 1996, p. 82).

Conforme resume Monica Rebecca Nunes:

Para compreender a cultura como semiosfera, $[\ldots]$ temos que entender que a fronteira responde justamente pela possibilidade de um espaço comunicar-se com o outro, codificando de modo estranho a uma semiosfera dada. A cultura, então, cria sua organização interna e igualmente seu tipo de desorganização externa, que, graças à fronteira, pode ser absorvida, de modo que o que parecia choque pode se transformar em encontro e resultar em produção de inusitados sistemas de signos, códigos, textos e linguagens, isto é, em uma nova informação, reforçando o dinamismo, o dialogismo e o continuum cultural (NUNES, 2011, p. 20).

Pensada como semiosfera, a música eletrônica possui um núcleo mais estável, definidor de seus aspectos menos variáveis, e fronteiras que traduzem os trechos sampleados de outras origens (não-textos tornados textos). Nessa semiosfera, o DJ experimental trabalha nas zonas de fronteira, por buscar sempre a hibridização com dados sonoros estranhos 
ao mainstream. Se a música eletrônica, fundada na colagem e na mistura, já se configura como sistema dinâmico, os DJs experimentais são os que potencializam ainda mais esse movimento tradutório, pois optam, muitas vezes, por materialidades sonoras de culturas não ocidentais. Distantes do núcleo, acionam em suas criações elementos desse centro e de outras semiosferas e se posicionam no campo instável das mediações produtivas.

D) Tudo constrói seu trabalho nas confluências de músicas estranhas entre si. Um exemplo é seu disco Pancada Motor - Manifesto da Festa (2015). Nele, cada faixa é uma mixagem de instrumentos e timbres distintos. A lógica interna (rítmica e melódica) de cada faixa reorganiza os sentidos dos elementos de fora. No vídeo teaser ${ }^{15}$ para o lançamento da obra, ficam explícitos os elementos sonoros, suas respectivas origens e como são agenciados nas peças: há vozes de cantos tradicionais, gravações de músicas de folguedos brasileiros como marujada, caboclinho etc., sons de rabeca, instrumentos de sopro, guitarra, percussões variadas, um baglama saz (guitarra turca) elétrico, entre outros instrumentos. Cada som é gravado digitalmente e se torna um dado sonoro a ser reordenado (tornado texto dentro da nova semiosfera) a partir da mixagem com outros sons sintéticos. O que era não-texto se organiza dentro do novo texto musical criando novos sentidos numa zona de fronteira que tensiona o reconhecimento e a escuta. Por envolver instrumentos acústicos, a própria definição de música eletrônica passa a ser questionada. A peça ressemiotiza vários estilemas musicais em camadas e, como corpo poroso, trabalha novas informações e novas sintaxes sonoras. Mesmo que a obra se baseie num regime aberto de contatos, misturas e adaptações, comum aos DJs, a radicalidade e a criatividade das traduções definem o experimentalismo desses DJs.

O Psilosamples, na faixa HUNI KUINS Yame Awa Kawanai dance (degust/Amazonian splashdown $)^{16}$, provoca uma junção inusitada. Suas matérias-primas são a fala de um indígena do povo Huni Kuin (ou Kaxinawá), um canto huni kuin chamado Yame Awa Kawanai e os timbres e efeitos sonoros digitais do seu equipamento. O canto huni kuin fala dos animais encantados da noite, os espíritos e os homens. Serve para cura e para manter a força (MATTOS, 2015). A faixa tem atmosfera mais intimista e explora texturas sonoras com batida não muito rápida, distante da dança. Sua criação se dá numa fronteira imprecisa e difícil. Os trechos sampleados são não-textos porque em nada produzem sentido para a semiosfera da música ocidental. No entanto, na música eletrônica, os samples são reordenados a partir de critérios estéticos e como registro de estranhamento, daí a radicalidade operada nessa tradução musical.

Outro exemplo é a faixa Tomora ${ }^{17}$, de Dandara, que usa recortes sonoros misturados a elementos sintéticos (samples, beats, loops) e samples de frases cantadas por artistas como Ogoya Nengo (Quênia), que usa idiomas locais, diferente do inglês da música pop globalizada, ou outros idiomas considerados "oficiais" na concepção moderna.

15 Disponível em <https://www.youtube.com/watch?v=CXHkN5fe18g>.

16 <https://soundcloud.com/psilosamples/huni-kuins-yame-awa-kawanai-dance-degust-amazonian-splashdown>.

$17<$ https://soundcloud.com/dandara_and_arutani/tomora?in=dandaramusic/sets/goodies >. 


\section{Memória da cultura e cultura como memória}

A segunda categoria vinculada à semiótica da cultura que se mostra produtiva na análise da música de DJs experimentais é a relação entre memória e cultura. Quando citamos as características do texto cultural como um dispositivo que guarda, transforma e gera informações, estamos também diante de um mecanismo que produz memória.

[...] texto cultural com funções de comunicação, de geração de sentido e de memória, porque o texto condensa informações, não só recebe informações de fora dele, mas também as ocasiona, e, assim, adquire memória. Na heterogeneidade da semiosfera, o intercâmbio entre os diferentes textos pode ser concebido como dialógico. E é neste trânsito que ocorrem as confluências imprevisíveis, criando novas organizações de linguagem, novos textos de cultura (NUNES, 2014, p. 228).

Memória da cultura se aproxima de um tipo peculiar de memória coletiva e tem a ver com o entendimento da cultura como memória, ou seja, cultura como um mecanismo de processamento de informações, um dispositivo tradutor. Nela, textos ancestrais (tradições e culturas locais) ou de espaços mais distantes podem ser reorganizados e ressemantizados em novos contextos. Sempre dinâmica, a cultura não pode ser pensada como um mero depósito "[...] en el que están apilados los mensajes, invariantes en su esencia y siempre equivalentes a sí mismos" (LOTMAN, 1998, p. 157), mas a partir da qual textos e sentidos são reordenados, traduzidos ou regenerados. Para o semioticista russo, cultura é memória, por ser uma espécie dinâmica de acervo de dados sempre disponíveis para serem recontextualizados, já que não são informações inertes, mas em constante atividade semiótica, conforme novas relações em diferentes contextos culturais:

Los aspectos semióticos de la cultura [...] se desarrollan, más bien, según leyes que recuerdan las leyes de la memoria, bajo las quales lo que pasó no es aniquilado ni passa a la inexistência, sino que, sufriendo uma selección y una compleja codificacción, passa a ser conservado, para, en determinadas condiciones, de nuevo manifestarse (LOTMAN, 1998, p. 153).

Numa relação temporal, é possível pensar em textos antigos que reaparecem em novas relações no presente, segundo demandas específicas, não de forma plena, mas em fragmentos ou enviesados, a serem rearticulados em novos textos.

Los estados pasados de la cultura lanzan constantemente al futuro de ésta sus pedazos: textos, fragmentos, nombres y monumentos aislados. Cada uno de estos elementos tiene su volumen de 'memoria'; cada uno de los contextos en que se inserta, actualiza certo grado de su profundidad (LOTMAN, 1998, p. 162). 
A noção de cultura como memória liga-se ao conceito de tradução: a partir de repertórios culturais anteriores, indivíduos e grupos reelaboram os textos culturais. Lotman chama esse processo de "tradução da tradição". Qualquer texto pode ser ressemantizado, em função de tensões, realinhamentos ou misturas. Os dados da tradição se mantêm e, ao mesmo tempo, se reestruturam para produzir novos sentidos e textos:

[...] cultura é uma acumulação histórica de sistemas semióticos (linguagens). A tradução dos mesmos textos para outros sistemas semióticos, a assimilação dos distintos textos, o deslocamento dos limites entre os textos que pertencem à cultura e os que estão além dos seus limites constituem o mecanismo da apropriação cultural da realidade. A tradução de uma porção determinada da realidade para uma das linguagens da cultura, sua transformação em texto, ou seja, em informação codificada de certa maneira, a introdução de tal informação na memória coletiva: esta é a esfera da atividade cultural cotidiana (LOTMAN apud VELHO, 2009, p. 254).

Como todo texto da cultura é formado por memórias, toda música é assim construída. No entanto, a música dos DJs é, por sua natureza híbrida, uma música de memórias. Essas obras e seus criadores devem ser tratados, assim, como dispositivos tradutores de textos culturais e memórias no sistema musical. A rigor, todos os artistas realizam alguma tradução cultural, em algum grau e de alguma forma. Mesmo um compositor considerado tradicional, em certa medida, realiza alterações formais em sua obra. No entanto, ao compararmos esses músicos mais próximos da tradição com os DJs experimentais, notamos grande distância, vez que esses DJs trabalham traduzindo textos de memórias midiáticas ou tradicionais de diferentes espaços e tempos. Ser adjetivado como experimental indica afastamento proposital e programático dos estilemas dos gêneros e tendência às hibridizações sonoras, que indeterminam as codificações marcadas por rótulos mercadológicos, com uso de instrumental diferenciado nos arranjos, entre outros elementos incorporados às composições. Nos três exemplos neste artigo, observamos a articulação de textos de origens variadas que representam, em alguma medida, memórias culturais distintas, de diferentes semiosferas. Usar um instrumento turco, a música de um folguedo nordestino, um canto indígena, um atabaque, uma guitarra distorcida ou qualquer outro instrumento, gênero musical, ritmo ou tipo de canto é invocar outras camadas de cultura profundas ou distantes. Mais do que uma simples relação individual e subjetiva com o passado, são narrativas coletivas ancestrais que se acumulam e se reorganizam a todo momento enquanto textos na cultura. É como se materiais sonoros, festivos e corporais já existentes em espaços e tempos distantes fossem traduzidos pelo DJ na sua criação, numa práxis artística que sugere outra ética criativa em relação à diversidade musical e cultural, para além dos regimes mais estáveis da música pop. Cada pedaço sonoro, por ter uma origem (conhecida ou não), reveste-se da função de memória. Quando o DJ manuseia tais trechos musicais, a cultura, seus sentidos e memórias são também rearticulados em novas sintaxes. 
As relações tensivas que se estabelecem fazem com que essas peças musicais experimentais não se conformem em estruturas reconhecidas. Ao contrário, fazem com que a semiosfera da música eletrônica se mova de maneira ainda mais intensa.

\section{Considerações finais}

O projeto estético de mistura, tradução e acionamento de novas semioses, os nomadismos culturais, as relações entre estilemas de gêneros, ritmos de tradições locais e o constante remexer de textos da memória musical na obra de alguns DJs mais experimentais são movimentos de experiência semiótica que produzem diferença e estranhamento no ambiente midiático. As disposições sonoras do sampler, das vozes e dos instrumentos, estruturadas em complexas materialidades acústicas geralmente à margem das grandes narrativas midiáticas, são novos caminhos que os artistas constroem em suas obras. Por meio da música, esses DJs descortinam memórias da cultura e exercitam as fronteiras culturais das semiosferas. Nessas regiões periféricas, afastadas do núcleo da música pop eletrônica (marcado por subgêneros e suas apropriações culturais, mas atuando dentro de alguns de seus modos de produção), outros textos emergem ressemantizados. Embora sejam produtores de diferença na memória midiática do pop, a densidade de sentidos que surge dessas rearticulações da memória é substância sígnica inerente às criações mais complexas. Para Lotman (1998, p. 155), "cuanto más complejo es un linguaje, cuanto más ajustado está para la transmisión y producción de información más compleja, tanto maior profundidad debe poseer su memoria".

As faixas aqui comentadas (poucas, porém representativas) sugerem variações formais, sintáticas, semânticas e até epistêmicas, pois tangenciam elementos não ocidentais. Reconhecidas ou não, suas presenças são experiências que nos tocam pela diferença, momento de epifania "no sentido de nos ocupar" (GUMBRECHT, 2010, p. 145). A escolha de cada elemento sonoro (timbres, ritmo) e material (instrumentos, voz, corpo) está relacionada a uma transformação, que também significa revisar as memórias excluídas por esquecimentos.

Essas obras experimentais encontram-se nas fronteiras, onde vigora um regime aberto de criação, de alteridade radical, fundado nas ações de tradução de textos da cultura. O DJ experimental se coloca no campo de tais mudanças ao propor novas narrativas na semiosfera da música eletrônica, às vezes na tentativa de escapar dos próprios rótulos dessa semiosfera. Sua subjetividade, corporificada em um produto midiático (a música nas mídias), demonstra as possibilidades de rearticulação dentro da própria dinâmica de disputas simbólicas da cultura midiática. 
Herom Vargas é professor do Programa de Pós-Graduação em Comunicação da Universidade Metodista de São Paulo - UMESP.

heromvargas50@gmail.com

Nilton Faria de Carvalho é doutorando no Programa de PósGraduação em Comunicação da Universidade Metodista de São Paulo - UMESP.

niltonblog@gmail.com

\section{Referências}

ASSEF, C. Psilosamples: o techno que saiu de Pouso Alegre e vai entortar o mundo, ouça antes Biohack Banana e leia o papo com Zé Rolê - Entrevista. Site Music Non Stop. 10 nov. 2016. Disponível em: https://musicnonstop.uol.com.br/psilosamples-o-techno-que-saiu-de-pouso-alegre-e-vai-entortar-omundo-ouca-antes-biohack-banana-e-leia-o-papo-com-ze-role/. Acesso em: 28 jan. 2018.

BAKHTIN, M. M. Os gêneros do discurso. In: Estética da criação verbal. São Paulo: Martins Fontes, 2003, p. 261- 306.

CONTER, M.; SILVEIRA, F. L. Sampleamento de imagens sonoras em Fear of a Black Planet. Resonancias, v. 19, n. 35, 2014, p. 47-60.

FERREIRA, A.; RABOT, J-M. Electronic dance music: discursive ambiguities. Lusophone Journal of Cultural Studies. v. 4, n. 2, 2017, p. 313-326.

GUMBRECHT, H. U. Produção de presença: o que o sentido não consegue transmitir. Rio de Janeiro: Contraponto, 2010.

KELLNER, D. A cultura da mídia. Bauru (SP): Edusc, 2001.

KRISTEVA, J. Desire in language: a semiotic approach to literature and art. New York: Columbia University Press, 1980.

LEVI, P. Cibercultura. São Paulo: Ed. 34, 1999.

LOTMAN, I. La semiosfera I. Semiótica de la cultura y del texto. Madrid/Valencia: Ediciones Cátedra/ Frónesis Universidad de Valencia, 1996.

La semiosfera II. Semiótica de la cultura, del texto, de la conducta y del espacio. Madrid/ Valencia: Ediciones Cátedra/Frónesis Universidad de Valencia, 1998.

MCLEOD, K. Genres, subgenres, sub-subgenres and more: musical and social differentiation within electronic/dance music communities. Journal of Popular Music Studies, n. 13, 2001, p. 59-75.

MATTOS, A. P. O sonho do nixi pae. A arte do MAHKU - Movimento dos Artistas Huni Kuin. ACENO: Revista de Antropologia do Centro-Oeste, v. 2, n. 3, jan/jul 2015, p. 59-77.

NAVAS, E. Remix theory: the aesthetics of sampling. New York: Springer-Verlag/Wien, 2012.

NUNES, M. R. F. Passagens, paragens, veredas: semiótica da cultura e estudos culturais. In.: SANCHES,

T. A. (org). Estudos culturais: uma abordagem prática. São Paulo: SENAC, 2011, p. 13-38. 
. A emergência da cena cosplay nas culturas juvenis. Significação: Revista de Cultura Audiovisual. São Paulo, v. 41, n. 41, 2014, p. 218-235.

PEREIRA DE SÁ, S. Música eletrônica e tecnologia: reconfigurando a discotecagem. In: LEMOS, A.; CUNHA, P. (org). Olhares sobre a cibercultura. Porto Alegre: Sulina, 2003, p. 153-173.

POLIVANOV, B. Apropriações de sites de redes sociais em cenas de música eletrônica: distinção, sociabilidade e marcas identitárias. Revista Interin. v. 17, n. 1, jan/jun 2014, p. 96-116.

RAMOS, A. V. et al. Semiosfera: exploração conceitual nos estudos semióticos da cultura. In: MACHADO, I. (org). Semiótica da cultura e semiosfera. São Paulo: Annablume/Fapesp, 2007, p. 27-44.

REYNOLDS, S. Generation Ecstasy: into the world of techno and rave culture. New York: Routledge.1999.

VALENTE, H. A. D. As vozes da canção na mídia. São Paulo: Via Lettera, 2003.

VARGAS, H.; CARVALHO, N. DJ Dolores: experimentation, difference and memory of the electronic music. Lusophone Journal of Cultural Studies, v. 5, n. 1, 2018, p. 263-278.

VARGAS, H.; CARVALHO, N. F. DJ Tudo, samples e hibridismos: da linguagem do estúdio para a apresentação ao vivo. Líbero, v. 19, n. 38, 2016, p. 59-68.

VELHO, A. P. M. Semiótica da cultura: apontamentos para uma metodologia de análise da comunicação. Revista de Estudos da Comunicação, v. 10, n. 23, set/dez 2009, p. 249-257. 